University of Nebraska - Lincoln

DigitalCommons@University of Nebraska - Lincoln

USDA National Wildlife Research Center - Staff

Publications

U.S. Department of Agriculture: Animal and Plant Health Inspection Service

January 2007

\title{
Dominance and neophobia in coyote (Canis latrans) breeding pairs
}

Alex Edward Mettler

Utah State University, Logan, UT

John Anthony Shivik

Utah State University, Logan, UT

Follow this and additional works at: https://digitalcommons.unl.edu/icwdm_usdanwrc

Part of the Environmental Sciences Commons

Mettler, Alex Edward and Shivik, John Anthony, "Dominance and neophobia in coyote (Canis latrans) breeding pairs" (2007). USDA National Wildlife Research Center - Staff Publications. 408.

https://digitalcommons.unl.edu/icwdm_usdanwrc/408

This Article is brought to you for free and open access by the U.S. Department of Agriculture: Animal and Plant Health Inspection Service at DigitalCommons@University of Nebraska - Lincoln. It has been accepted for inclusion in USDA National Wildlife Research Center - Staff Publications by an authorized administrator of DigitalCommons@University of Nebraska - Lincoln. 


\title{
Dominance and neophobia in coyote (Canis latrans) breeding pairs
}

\author{
Alex Edward Mettler ${ }^{\mathrm{a}, *}$, John Anthony Shivik ${ }^{\mathrm{b}, 1}$ \\ ${ }^{a}$ Department Forest, Range, and Wildlife Sciences, Utah State University, Logan, UT 84322, USA \\ ${ }^{\mathrm{b}}$ USDA Wildlife Services, National Wildlife Research Center, and Utah State University, \\ Room 163 BNR Building, Utah State University, Logan, UT 84322, USA
}

Accepted 15 March 2006

Available online 25 April 2006

\begin{abstract}
Previous research suggests that within social animals, subordinate individuals are less neophobic than dominant individuals. We investigated the effect of social status on neophobic responses using 10 captive coyote breeding pairs. Social status was determined from observations of feeding behavior and agonistic interactions during a series of reference trials. Once dominance was established, we surrounded an experimental area with novel stimuli (ropes adorned with interspersed flags) to create a novel context around a familiar food source. Contrary to hypotheses, dominant coyotes were first to feed, showed more interest toward novel stimuli, and eventually crossed the barrier, which subordinates never did. Our results indicate that dominant coyotes are less neophobic of novel settings that contain familiar food than subordinates are. Since a reduction in neophobia can be interpreted as an increase in risk taking, our results support previous observations that dominant (alpha) coyotes take more risks than subordinates. Our results also suggest reasons for differential observations of coyote behavior in the field: artificial selection against bold behavior in populations undergoing predator control.
\end{abstract}

(C) 2006 Elsevier B.V. All rights reserved.

Keywords: Neophobia; Dominance; Coyote; Fladry

* Corresponding author at: 8245 W. Broadway, Forest Lake, MN 55025, USA. Tel.: +1 4357706570

E-mail addresses: aemettler1@yahoo.com (A.E. Mettler), jshivik@cc.usu.edu (J.A. Shivik).

${ }^{1}$ Tel.: +1 4357971348 .

0168-1591/\$ - see front matter (C) 2006 Elsevier B.V. All rights reserved. 


\section{Introduction}

Neophobia, the fear of novelty, is typified by hesitation, avoidance, or caution (Barnett, 1958; Harris and Knowlton, 2001) and is an indicator of an animal's internal state of risk perception as well as its degree of boldness, or propensity to take risks (Wilson et al., 1994). Neophobic responses to objects and food have been documented in numerous species (Marples and Kelly, 1999) and differential response within and between species has been the subject of much study (Wilson et al., 1994).

Neophobic phenomena can be used to resolve ecological and evolutionary questions in the context of social dominance and risk avoidance. For example, considerable evidence suggests that subordinate animals forage in riskier environments than dominants (Lange and Leimar, 2001) because dominant animals control preferential access to food resources (Wrangham, 1981; McClintock et al., 1982) and can displace subordinates from them. For subordinates to use riskier or novel alternatives, they must overcome fear associated with novel or otherwise risky environments. Thus, neophobia is hypothesized to be weaker or less prevalent in subordinate than in dominant individuals.

That different animals express different behavioral repertoires (e.g. personalities) is acknowledged, but the differing degree of boldness in dominant and subordinate animals is only beginning to be understood (Dingemanse and De Goede, 2004). Dominant rats (Rattus norvegicus) were shown to be more neophobic than subordinates (Robertson, 1982), and subordinate jackdaws (Corvus monedula) usually initiate feeding in novel situations (Katzir, 1983). Alternatively, boldness in trout (Salmo trutta) was positively associated with dominance (Sundström et al., 2004).

Neophobia in coyotes (Canis latrans) has been examined in substantial detail (Windberg, 1996; Harris and Knowlton, 2001; Heffernan, 2002). Relative to coyote hierarchies (Knight, 1978; Bekoff and Wells, 1980), dominant coyotes (3-6 months old) were more neophobic than subordinates (Johnson and Balph, 1990). The case of coyotes is particularly interesting, however. In natural conditions only dominant coyotes pursue and kill large dangerous prey and lead repelling of intruding conspecifics (Gese and Grothe, 1995), which suggests that dominant coyotes are more bold than subordinates. However, from field observations, Sacks et al. (1999) and Séquin et al. (2003) concluded that dominant coyotes were more wary (i.e. less bold or more neophobic) because they were less susceptible to photo and mechanical capture.

Coyote management programs that utilize visual stimuli may benefit from a better understanding of coyote neophobia and dominance. Coyotes that are less neophobic of control devices (e.g. cyanide guns and traps) are more likely to be captured or removed. Knowing which coyotes are less neophobic and therefore more susceptible to capture may be helpful to managers. Our objective was to experimentally examine the interplay between dominance and neophobia in adult coyotes in order to understand how dominant coyotes are sometimes observed to be more bold and at other times less bold than subordinates.

\section{Methods}

We conducted experiments at the Wildlife Services, National Wildlife Research Center, Predator Research Facility in Millville, Utah. We used 10 breeding pairs of coyotes to 
examine dyad dominance relationships. All coyotes were $>24$ months of age and born in captivity. Eighteen were hand-raised, while two were parent-raised. Pairs were housed and tested in separate 0.1 -ha wedge-shaped pens, vegetated with a short $(15 \mathrm{~cm})$ grass/alfalfa mixture. Each pen contained two sun shelters, a water nozzle, and a den box that extended into an adjoining observation building. Under maintenance conditions, coyotes were fed by technicians and received $400 \mathrm{~g}$ of commercial mink food each, once a day. Pair members were fed simultaneously by forming two separate piles, placed $>5 \mathrm{~m}$ apart.

\subsection{Pre-treatment trials}

To ensure that pen conditions were familiar, we allowed coyote pairs to reside for $>14$ days in their test pens prior to testing (Windberg, 1996; Harris and Knowlton, 2001). During the familiarization period, we demarcated a $(7 \mathrm{~m})^{2}$ "experimental zone" with 1$\mathrm{m} \times 0.6-\mathrm{cm}$ metal reinforcement bar posts midway along the cement wall boundary (Fig. 1). Subjects were fed, as normal, the day before each trial, but they were not fed as normal on the day of the trial. Rather, a trial consisted of a 1-h observation period that began when their daily ration was instead placed at the center of the delineated experimental zone. For each trial, a technician walked in through the gate (Fig. 1) and along the perimeter fence to the experimental zone. Then the technician walked the perimeter of the experimental zone, before placing the food in a single pile on the ground, in the center.

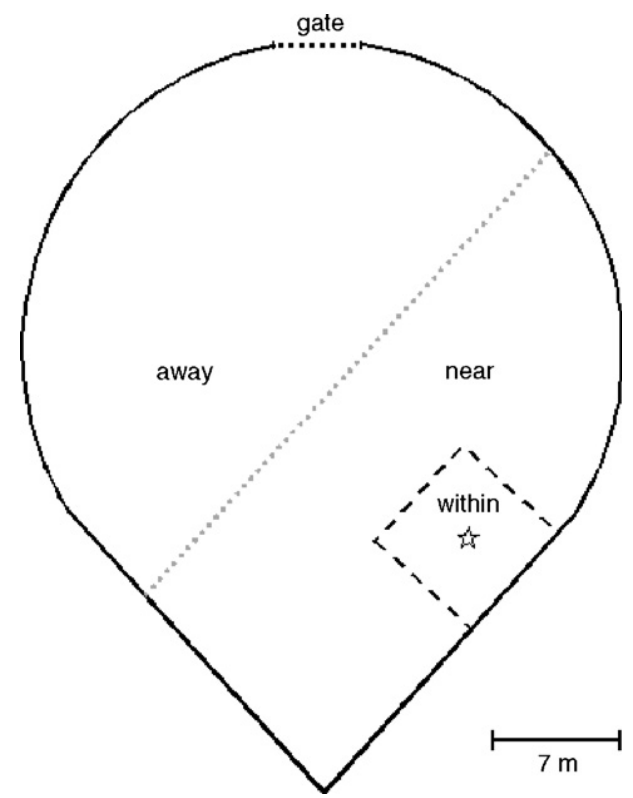

Fig. 1. Schematic of 0.1-ha pen used in pre-treatment and fladry experiments at Millville, UT, OctoberNovember, 2004. Solid line marks pen perimeter. Dashed line represents experimental zone perimeter. Star marks food position. The gate used for entry is labeled. The dotted line across the middle of the pen indicates invisible boundary used for space use data. The three space use categories used in analysis are labeled on the diagram. 
Coyotes were allowed to move freely within the pen during food placement. We observed trials from behind one-way glass inside the pen's observation building. Pairs were not given additional food after each trial, but resumed their normal feeding schedule and placement the following day. Each pair was tested and observed for four 1-h trials over the course of 2 weeks (once every 3-4 days).

\subsection{Treatment trials}

To create a novel context, we employed ropes adorned with interspersed pieces of flagging around the perimeter of the experimental zone, commonly referred to as fladry (Carol's Creations, Arco, Idaho). Fladry was traditionally used in hunts in Eastern Europe to funnel gray wolves (Canis lupus) into a small area (Okarma, 1993) and has been shown to elicit neophobia in captive (Musiani and Visalberghi, 2001) and wild wolves (Musiani et al., 2003). Our fladry was composed of blue, nylon twine from which hung red plastic flags $(50 \mathrm{~cm}$ long by $8 \mathrm{~cm}$ wide) spaced at $50 \mathrm{~cm}$ intervals.

Treatment trials followed the completion of the pre-treatment trials. The procedure was identical to the pre-treatment trials, except that technicians strung fladry along the boundary of the experimental zone prior to placing food at the center. We tested and observed each pair for four 1-h trials over the course of 2 weeks (one trial per pair every 3-4 days). After each 1-h trial, a technician removed the fladry line and the food if it had not been eaten.

We conducted further observations for pairs that did not enter the experimental zone and eat the food during the initial 2-week trial period. The subsequent observations began $48 \mathrm{~h}$ after the final 1-h trial. Technicians replaced fladry lines and food as per the previous trials but left the novel stimuli and food in place for $96 \mathrm{~h}$. Continuous observations were recorded on videotape. In addition to the food in the experimental zone, we provided a daily ration's worth of food every $24 \mathrm{~h}$ outside of the experimental zone to ensure that the coyotes did not become nutritionally depleted.

\subsection{Data analysis}

We defined a coyote as dominant when it always experienced favorable outcomes, or "wins", in interactions and exhibited repeated aggressive behaviors toward the other member of the dyad (Drews, 1993). In our trials, a "win" was gaining exclusive access to food. Aggressive behaviors included chase (rapid pursuit), bite (jaws close briefly on mate), and stand-over (body positioned over mate; ears and tail high).

We used Observer 5.0 (Noldus Information Technologies, 2003) to score and tabulate observations. For the 1-h trials and the extended, 96-h trials, we recorded the latency to enter the experimental zone and we noted which pair member was first to enter (i.e. "win"). For the 1-h trials, we also recorded behavior and space use for each coyote. Behaviors were grouped into two categories: behaviors toward food/fladry (approach, enter experimental zone, eat) and aggressive behaviors toward mate. We defined three areas within each pen to measure space use. Coyotes could be within the experimental zone, near the experimental zone (i.e. in the half of the pen containing the experimental zone), or away from the experimental zone (Fig. 1). We defined an approach as moving from the "away" zone to the "near" zone. We quantified behavior by tallying behavioral events and 
quantified space use by calculating space use budgets (i.e. duration of time in each zone). From the event tallies and the space use budgets, we calculated mean values for each coyote across the four 1-h trials for both pre-treatment and treatment stages.

We evaluated space-use and behavioral differences between pair members with one-way analysis of variance (ANOVA), and we evaluated interactions between social status and treatment with two-way ANOVA with repeated measures on one factor (Ott, 1998) using SAS software (SAS Institute Inc., 2004). We examined the effects of pre-treatment versus treatment with the hypothesis that an interaction between social status and treatment would be apparent; specifically, dominant coyotes would normally control access to food, but in a novel context, subordinate coyotes would be less neophobic and better able to acquire food.

\section{Results}

Food dominance among pairs during the control trials was unambiguous; within all 10 pairs, the same individual always ate all of the food in the pre-treatment experimental area. There was a potential, but not strong (Wilcoxon rank test: $P=0.20$ ) sex bias in dominance because seven of the food dominant individuals were male and three were female. Food dominant coyotes exhibited significantly more $\left(F_{1,9}=41.30, P<0.001\right)$ aggressive behavior than subordinate coyotes during pre-treatment and treatment trials.

All coyotes spent significantly less time $\left(F_{1,18}=16.93, P<0.001\right)$ near the experimental zone during treatment trials than during pre-treatment trials. During the treatment trials, dominant individuals spent more time near the experimental zone $\left(F_{1,9}=7.07, P=0.02\right)$. We did not find a significant interaction $\left(F_{1,18}=2.45, P=0.13\right)$ between dominants and subordinates by treatment for time spent near the experimental zone (Fig. 2).

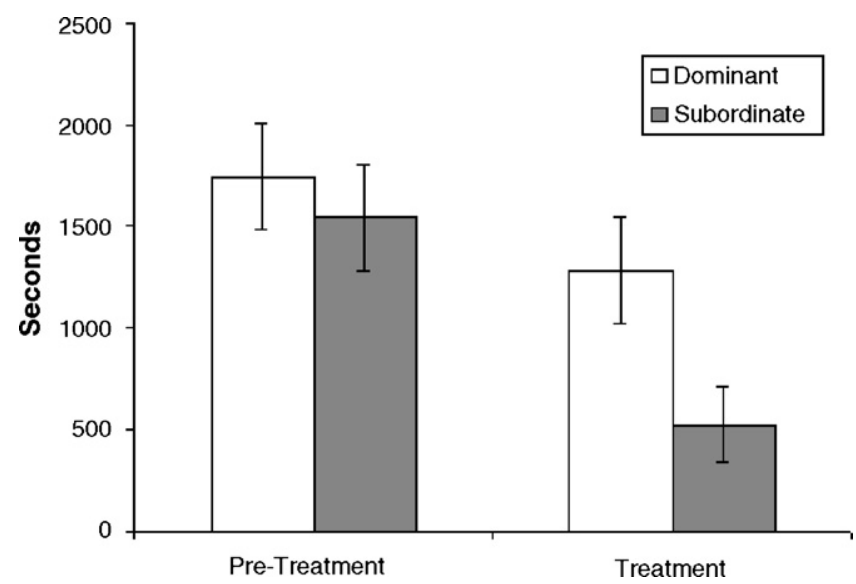

Fig. 2. Mean time in seconds ( \pm 1 S.E.) spent near experimental zone by rank and treatment for captive coyotes at Millville, UT from October-November, 2004. There is a significant difference between pre-treatment and treatment for dominants and subordinates combined $\left(F_{1,18}=16.93, P<0.001\right)$ and also between dominants and subordinates during treatment trials $\left(F_{1,9}=7.07, P=0.02\right)$. 
Coyotes approached the experimental zone significantly more $\left(F_{1,18}=10.99\right.$, $P=0.004)$ during treatment trials than during pre-treatment trials. Specifically, dominants approached the experimental zone more than subordinates during the treatment trials at near significant levels $\left(F_{1,9}=4.03, P=0.06\right)$. Furthermore, we found a significant $\left(F_{1,18}=6.18, P=0.02\right)$ interaction between dominants and subordinates by treatment. However, the interaction was in the opposite direction as that hypothesized; dominants approached more than subordinates during treatment trials (Fig. 3).

Coyotes entered the experimental zone significantly less $\left(F_{1,18}=83.17, P<0.001\right)$ during treatment trials than pre-treatment trials. Specifically, dominants entered the experimental zone more than subordinates $\left(F_{1,9}=4.88, P=0.04\right)$. We observed a significant interaction $\left(F_{1,18}=0.45, P=0.05\right)$ between dominants and subordinates by treatment. However, the interaction was in the opposite direction to that hypothesized; dominants entered the experimental zone more than subordinates during treatment trials (Fig. 4).

Coyotes spent significantly less time $\left(F_{1,18}=22.15, P<0.001\right)$ within the experimental zone during treatment trials than during pre-treatment trials. Time spent within the protected zone differed by rank at near significant levels $\left(F_{1,9}=4.10, P=0.06\right)$, with dominants spending more time in the experimental zone than subordinates. We did not find a significant interaction $\left(F_{1,18}=0.76, P=0.40\right)$ between dominants and subordinates by treatment (Fig. 5).

Only two coyotes (from two different pairs) entered the experimental zone during the 1h observational trials. During the extended 96-h observations, all but one of the pairs entered the experimental zone. For all nine entering pairs, the initial entering coyote was the dominant individual. Mean latency to feeding for pre-treatment trials $(\bar{X} \pm$ S.E. $=$ $37.9 \pm 110.32 \mathrm{~s}, n=10)$ was much shorter than mean latency to feeding for treatment trials $(\bar{X} \pm$ S.E. $=186.130 \pm 43.749 \mathrm{~s}, n=9)$.

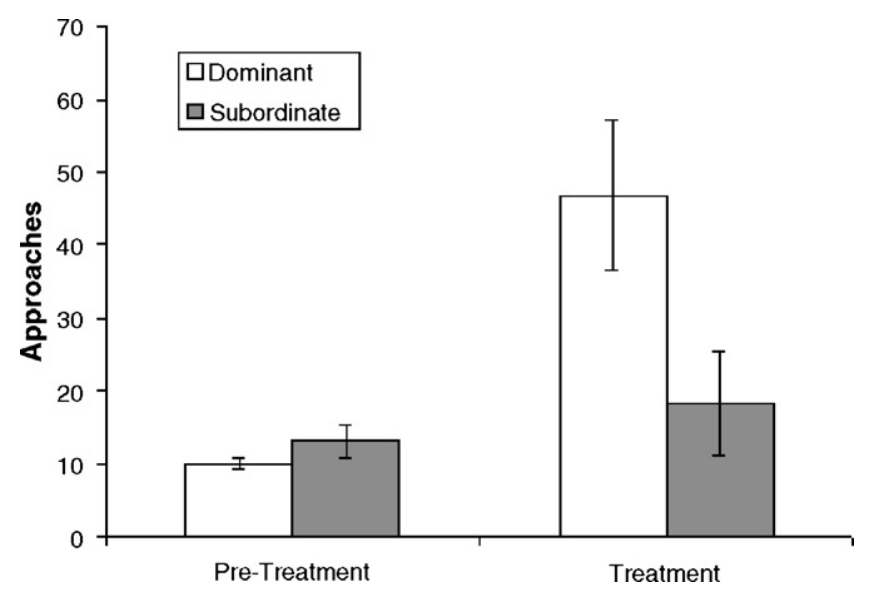

Fig. 3. Mean number of approaches ( \pm 1 S.E.) toward experimental zone by rank and treatment for captive coyotes at Millville, UT from October-November, 2004. There is a significant difference between pre-treatment and treatment for dominants and subordinates combined $\left(F_{1,18}=10.99, P=0.004\right)$ and a near significant difference between dominants and subordinates during the treatment trials $\left(F_{1,9}=4.03, P=0.06\right)$. There is a significant interaction between dominants and subordinates by treatment $\left(F_{1,18}=6.18, P=0.02\right)$. 


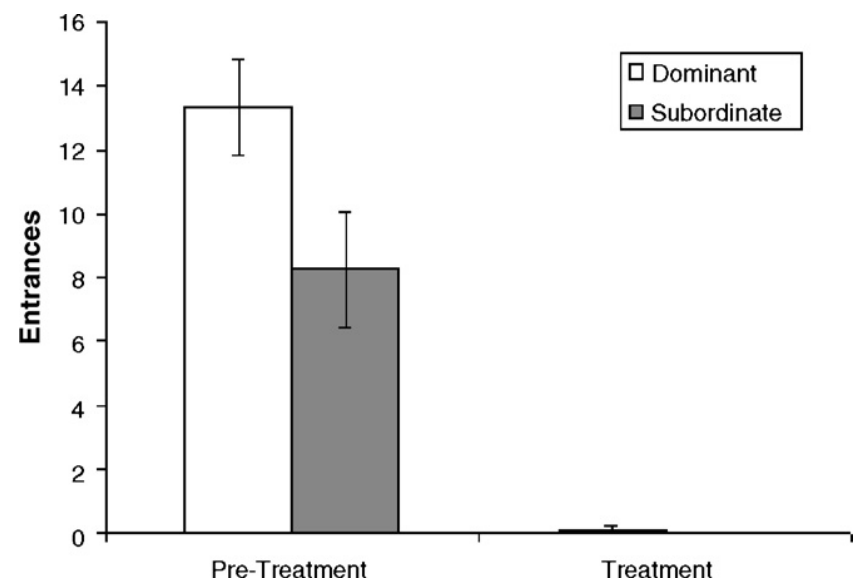

Fig. 4. Mean number of entrances ( \pm 1 S.E.) into the experimental zone by rank and treatment for captive coyotes at Millville, UT from October-November, 2004. There is a significant difference between pre-treatment and treatment for dominants and subordinates combined $\left(F_{1,18}=83.17, P<0.001\right)$ and between dominants and subordinates during treatment trials $\left(F_{1,9}=4.88, P=0.04\right)$. There is a significant interaction between dominants and subordinates by treatment $\left(F_{1,18}=0.45, P=0.05\right)$.

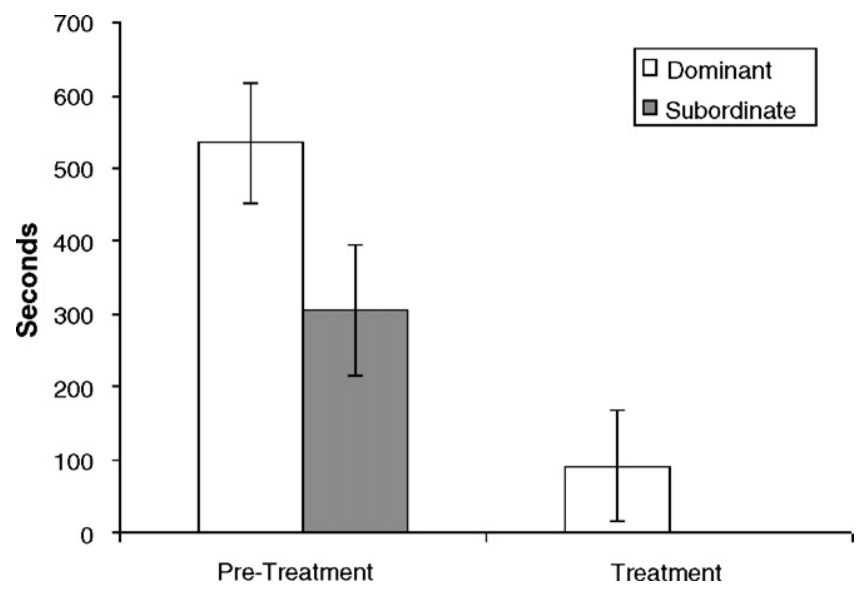

Fig. 5. Mean time in seconds ( \pm 1 S.E.) spent in experimental zone by rank and treatment for captive coyotes at Millville, UT from October-November, 2004. There is a significant difference between pre-treatment and treatment for dominants and subordinates combined $\left(F_{1,18}=22.15, P<0.001\right)$ and a near significant difference between dominants and subordinates during treatment trials $\left(F_{1,9}=4.10, P=0.06\right)$.

\section{Discussion}

Using "first to feed" as a measure to determine within pair dominance resulted in unambiguous results: during all four pre-treatment trials, the same coyote within each dyad was the first to feed. These food-dominant coyotes also exhibited more aggressive behavior toward their mates, which suggests food-dominant coyotes are also dominant in general. 
Trials using other, non-food resources (e.g. water, shelter) might provide further evidence of general social dominance. We saw some indication of sex-associated dominance, as did Brand et al. (1995) who found a difference in exploratory behavior in black-backed jackals (Canis mesomelas) based on sex, but males were not exclusively dominant.

We were not surprised to find that fladry elicited a strong neophobic reaction that required over $12 \mathrm{~h}$ of exposure before habituation occurred. However, we had hypothesized that subordinate coyotes would be the first to enter the experimental zone during the treatment trials, yet dominants were the first to enter in all cases. In fact, during the course of the trials, only one subordinate ever crossed the fladry line.

There are several possible explanations for our results differing from previous studies. Our study differed from those of Johnson and Balph (1990), Robertson (1982), and Katzir (1983) in that we used adult coyotes and had a familiar food in a novel context rather than a novel food in a familiar setting. It is possible that age and food versus context neophobia interact with dominance expression. However, our results were consistent with those of Knobel and Du Toit (2003) who suggested that initial low consumption of novel rabies vaccine baits by subordinate wild dogs (Lycaon pictus) was due to the fact that the dominant wild dogs readily consumed baits, and even defended them from pack members. Additionally, in observations of captive gray wolf responses to novel stimuli, food dominance within breeding pairs did not change in the presence of novelty (Mettler, 2005).

Relative to the ecology of coyotes, our results suggest that adult dominant coyotes are less risk averse than subordinates, which is consistent with observations of wild coyote packs where dominant animals attack larger, more dangerous prey (Mech and Nelson, 1990) and subordinates are limited to small, innocuous prey (Bowen, 1981; Gese and Grothe, 1995; Gese et al., 1996). Similarly, in agricultural and ranching landscapes dominant coyotes are responsible for a majority of sheep depredations (Sacks et al., 1999). Why do dominant coyotes expend effort to kill when they could reduce risk by displacing subordinate coyotes that have killed larger prey? In a behavioral context, under such an "enslaved subordinate" scenario, subordinates receive no reinforcement for risk-taking because they can consume little of the riskier prey; the behavior will be extinguished (Baldwin and Meese, 1979; Dawkins, 1989). Therefore, coyote social structure is stabilized by adopting independent foraging strategies for dominant and subordinate animals (Gese et al., 1996).

If dominant coyotes are more bold, less neophobic, and otherwise less risk averse than subordinate animals, why then did Sacks et al. (1999) observe that dominant, alpha coyotes were less susceptible than low-ranking, subordinate coyotes to novel objects and traps? How does such a socio-behavioral system arise? Do bold individuals become dominant, or do dominant individuals become bold (Wilson et al., 1994)?

Based on our results and those of Johnson and Balph (1990), dominant animals become bold as they mature, but to explain differences in observed coyote behavior between field studies, we hypothesize that an important component of coyote behavioral ecology in areas of intensive management is artificial selection. That is, if animals are not neophobic of mechanical devices and lures, they are lethally removed from the population (they do not have the opportunity to learn to be wary). In such circumstances, young animals cannot become bold. Rather, in areas with ongoing coyote control programs (e.g. Sacks et al., 1999), neophobic coyotes are selected for (by removal of bold animals); persistent trapping 
results in capture bias toward young bold animals, and an increase in survival of animals that are not susceptible to capture. Thus, neophobic individuals increase in areas with intensive coyote removal and management because coyotes that survive to become breeding coyotes are those that are less susceptible to management methods. Field studies of coyote behavior, as well as that of other species, under different human-induced selective pressures would be useful for a better understanding of the interplay between dominance, neophobia, and survival.

\section{Acknowledgments}

We thank the staff, especially, Stacy Brummer, Patrick Darrow, Jeff Schultz, and Doris Zemlicka of the National Wildlife Research Center's Predator Ecology Facility in Millville, UT for their valuable assistance during experimental trials, P. McHugh and S. Durham for statistical assistance. The study was funded by Wildlife Services National Wildlife Research Center and all animal use was approved by the National Wildlife Research Center's and Utah State University's Institutional Animal Care and Use Committees.

\section{References}

Baldwin, B.A., Meese, G.B., 1979. Social behaviour in pigs studied by means of operant conditioning. Anim. Behav. 27, 947-957.

Barnett, S.A., 1958. Experiments on 'neophobia' in wild and laboratory rats. Br. J. Psychol. 49, $195-201$.

Bekoff, M., Wells, M.C., 1980. The social ecology of coyotes. Sci. Am. 242, 130-148.

Bowen, W.D., 1981. Variation in coyote social organization: the influence of prey size. Can. J. Zool. 59, 639-652.

Brand, D.J., Fairall, N., Scott, W.M., 1995. The influence of regular removal of black-backed jackals on the efficiency of coyote getters. S. Afr. J. Wildlife Res. 25, 44-48.

Dawkins, R., 1989. The Selfish Gene. Oxford University Press, New York.

Dingemanse, N.J., De Goede, P., 2004. The relation between dominance and exploratory behavior is contextdependent in wild great tits. Behav. Ecol. 15, 1023-1030.

Drews, C., 1993. The concept and definition of dominance in animal behaviour. Behaviour 125, $283-313$.

Gese, E.M., Grothe, S., 1995. Analysis of coyote predation on deer and elk during winter in Yellowstone National Park, Wyoming. Am. Midl. Nat. 133, 36-43.

Gese, E.M., Ruff, R.L., Crabtree, R.L., 1996. Foraging ecology of coyotes (Canis latrans): the influence of extrinsic factors and a dominance hierarchy. Can. J. Zool. 74, 769-783.

Harris, C.E., Knowlton, F.F., 2001. Differential responses of coyotes to novel stimuli in familiar and unfamiliar settings. Can. J. Zool. 79, 2005-2013.

Heffernan, D.J., 2002. Evaluation of multiple cues for increasing attraction of coyotes (Canis latrans), MS Thesis, Colorado State University.

Johnson, W.E., Balph, D.F., 1990. Resource acquisition in the presence of novelty by coyotes of different rank. J. Wildlife Manage. 54, 582-586.

Katzir, G., 1983. Relationships between social structure and response to novelty in captive jackdaws, Corvus monedula L. II. Response to novel palatable food. Behaviour 87, 183-208.

Knight, S.W., 1978. Dominance hierarchies of captive coyote litters, MS Thesis, Utah State University.

Knobel, D.L., Du Toit, J.T., 2003. The influence of pack social structure on oral rabies vaccination coverage in captive African wild dogs (Lycaon pictus). Appl. Anim. Behav. Sci. 80, 61-70.

Lange, H., Leimar, O., 2001. The influence of predation risk on threat display in great tits. Behav. Ecol. 4, 375380 . 
Marples, N.M., Kelly, D.J., 1999. Neophobia and dietary conservatism: two distinct processes? Evol. Ecol. 13, 641-653.

McClintock, M.K., Anisko, J.J., Adler, N.T., 1982. Group mating among Norway rats. II. The social dynamics of copulation: competition, cooperation, and mate choice. Anim. Behav. 30, 410-425.

Mech, L.D., Nelson, M.E., 1990. Evidence of prey-caused mortality in three wolves. Am. Midl. Nat. 123, 207208.

Mettler, A.E., 2005. Investigations into behavioral responses of predators to novel visual Stimuli, MS Thesis, Utah State University.

Musiani, M., Mamo, C., Boitani, L., Callaghan, C., Gates, C.C., Mattei, L., Visalberghi, E., Breck, S., Volpi, G., 2003. Wolf depredation trends and the use of fladry barriers to protect livestock in Western North America. Conserv. Biol. 17, 1538-1547.

Musiani, M., Visalberghi, E., 2001. Effectiveness of fladry on wolves in captivity. Wildlife Soc. B 29, 91-98. Noldus Information Technologies, 2003. The Observer 5.0. Noldus Information Technologies, Wageningen.

Okarma, H., 1993. Status and management of the wolf in Poland. Biol. Conserv. 66, 153-158.

Ott, R.L., 1998. An Introduction to Statistical Methods and Data Analysis. Duxbury Press, Belmont.

Robertson, D., 1982. Dominance and neophobia in rats. Behav. Neural Biol. 35, 91-95.

Sacks, B.N., Jaeger, M.M., Neale, J.C.C., McCullough, D.R., 1999. Territoriality and breeding status of coyotes relative to sheep predation. J. Wildlife Manage. 63, 593-605.

SAS Institute Inc., 2004. SAS. Cary, North Carolina.

Séquin, E.S., Jaeger, M.M., Brussard, P.F., Barrett, R.H., 2003. Wariness of coyotes to camera traps relative to social status and territory boundaries. Can. J. Zool. 81, 2015-2025.

Sundström, L.F., Petersson, E., Höjesjö, J., Johnsson, J.I., Järvi, T., 2004. Hatchery selection promotes boldness in newly hatched brown trout (Salmo trutta): implications for dominance. Behav. Ecol. 15, 192-198.

Wilson, D.S., Clark, A.B., Coleman, K., Dearstyne, T., 1994. Shyness and boldness in humans and other animals. Trends Ecol. Evol. 11, 442-446.

Windberg, L.A., 1996. Coyote responses to visual and olfactory stimuli related to familiarity with an area. Can. J. Zool. 74, 2248-2253.

Wrangham, R.H., 1981. Drinking competition in ververt monkeys. Anim. Behav. 29, 904-910. 